\title{
A IDENTIFICAÇÃO \\ E OS PROCESSOS DE SEGREGAÇÃO NA CONTEMPORANEIDADE
}

Pontifícia Universidade Católica de Minas Gerais - PUC Minas. Doutorando. Psicólogo.

Pontifícia Universidade Católica de Minas Gerais - PUC Minas. Doutorando. Bolsista de produtividade em Pesquisa, $\mathrm{CNPq}$, nível PQ-2. Psicólogo. Membro da Escola Brasileira de Psicanálise (Brasil) e da Associação Mundial de Psicanálise (Paris, França)

\section{Carlos Eduardo Pereira Ilka Franco Ferrari}

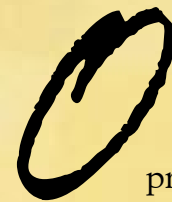

processo de identificação é essencial na discussão contemporânea sobre os laços sociais e as novas formas de segregação, e está intimamente ligado aos sentimentos de aversão e hostilidade presentes em toda relação afetiva que perdura por algum tempo. Esse "narcisismo das pequenas diferenças" estaria na base dos mecanismos que engendram os processos de segregação na cultura. Lacan retoma o tema da identificação proposto por Freud, que pode ser nomeada de histérica, narcísica ou imaginária, e diz da questão do outro em nós. Assim, a singularidade que marca o sujeito, sua identidade mais íntima é, para ele, ao mesmo tempo, estranha e exterior, o que nos remete ao que Freud (1919/1996) fez alusão em seu texto "O Estranho", e ao conceito lacaniano de extimidade. Para Lacan, a diferença em um grupo somente acontece pela hostilidade ou exclusão de outro diferente. Contemporaneamente, com a expansão da ordem capitalista e do ideal científico, assistimos à multiplicação de oferta de identificações que impõem uma homogeneização dos modos de gozo que podemos designar com uma manifestação do sintoma do Outro da cultura: aquilo que não vai bem e denuncia um disfuncionamento na relação entre os seres humanos e a cultura que os sustenta. Essas identificações segregam, na medida em que suas manifestações sinalizam pontos de fracasso no projeto de civilização, e podem ser tomadas como falhas no laço social. O fracasso escolar, o abuso de crianças, a violência urbana e as toxicomanias são exemplos dessas ocorrências.

Palavras-chave: Identificação. Segregação. Freud. Lacan. Contemporaneidade. 
A identificação, uma das matrizes constitutivas da subjetividade, é um conceito essencial na discussão dos laços sociais e formas de segregação na contemporaneidade. Este texto buscará elementos da teoria freudiana e lacaniana que nos permitam discutir as identificações, os laços sociais contemporâneos e suas vicissitudes.

Em Freud, no texto "Psicologia das massas e análise do Eu" (1921 - 1996), essa noção pode ser articulada em três perspectivas. A primeira delas faz alusão ao mito do pai primevo e é marcada pela incorporação do corpo mítico que funda o laço pela comunhão entre os membros do clã.

A segunda identificação, mais tarde desenvolvida, por Lacan, no Seminário19, é pelo traço. Essa identificação, nas próprias palavras de Freud (1921-1976, p.135) é "parcial e extremamente limitada, tomando emprestado apenas um traço isolado da pessoa que é o objeto dela" (FREUD, 1921 - 1976, p.135). E a terceira das identificações se baseia na receptividade a uma emoção semelhante e que une os elementos de um grupo através de uma qualidade emocional comum.

Freud reconhece que esses sentimentos narcísicos são efeitos da preservação de si mesmo e da ameaça de alteração do que lhe é próprio. Essa lógica que rege a estruturação dos grupos e comunidades acarreta, ao lado da fascinação pelos ideais ou pelo líder do grupo, um horror à diferença, que se torna signo de uma ameaça à coesão grupal.

Os sentimentos de aversão e hostilidade, presentes em toda relação com o outro, podem se apresentar sob a forma de ambivalência afetiva para com os que amamos; de manifestação narcísica aversiva aos que nos são estranhos; ou de um "narcisismo das pequenas diferenças", que se evidencia nas relações de proximidade.

Em Freud, o conceito de identificação é marcado pelo narcisismo como polo de oposição ao reconhecimento da diferença. Em termos normais, o "narcisismo das pequenas diferenças" está na base da constituição do "eu", do "nós" e do outro, na fronteira que tem por função resguardar o narcisismo da unidade. Quando levado ao paroxismo, desemboca na segregação e no racismo, expressões máximas da intolerância ao outro e tolerância ao mesmo.

Freud utilizou a noção de narcisismo das pequenas diferenças para refletir sobre par de opostos tolerância/intolerância, 
no plano individual e coletivo. Esse narcisismo é o que nos permite compreender por que o laço social, construído a partir de um ideal, ao mesmo tempo que favorece a sensação de pertencimento ao grupo, só pode se fortalecer na medida em que a cota de hostilidade sintetizada nas identificações seja canalizada para fora, princípio norteador das práticas segregativas.

É essa perspectiva que se complementa em outro texto freudiano: "O mal-estar da civilização" (1930/1996). Nesse texto, Freud ressaltará a impossibilidade do mandamento bíblico: "amarás a teu próximo como a ti mesmo" para o conjunto da humanidade. Uma vez que o amor é um bem precioso que exige uma cota de sacrifícios que devem valer a pena, aquele que é amado precisa merecer, de alguma maneira, o amor que lhe é dispensado. Esse merecimento pode surgir tanto da semelhança, de forma a podermos amar a nós mesmos no outro, como de uma superioridade que nos inspire amor ao ideal de nós mesmos. O limite do "ame ao próximo como a si mesmo" está no fato de que a identificação ao semelhante só é possível pela exclusão do não semelhante. Não há amor entre irmãos sem rejeição dos estrangeiros.

Lacan, no seminário 7, A Ética da Psicanálise (19591960/1988), realizará uma análise da elaboração de Freud sobre o mandamento do amor ao próximo e acentuará o elemento agressivo presente no laço com o outro, cuja origem é o próprio indivíduo; o masoquismo primário é um exemplo dessa presença. Em suas palavras "o que é mais próximo do que esse âmago em mim mesmo que é do meu gozo, do que não me ouso aproximar? Pois assim que me aproximo surge essa insondável agressividade diante da qual eu recuo, que retorna contra mim." (LACAN, 1988, p. 21). O conceito de gozo, nesse sentido, diz respeito a essa particularidade, subjetivação ou historização que o sujeito produz e reproduz de seu sofrimento.

Continuando com Lacan, a noção de identificação que ressaltaremos neste trabalho será aquela desenvolvida principalmente na década de 1960 no Seminário 9: A Identificação (1961-1962-2003), que colocará acento na relação do sujeito com o significante pelas vias do traço singular ou traço unário, tendo como base o segundo modelo proposto por Freud. Essa identificação consiste no surgimento do sujeito inconsciente, entendido como produto de um traço singular que se distingue no retorno a cada um dos significantes unificados ou articulados numa história. Esse traço unificador é 
apresentado como elemento externo e distinto do conjunto por ele unificado. Então, esse traço não é contável ou computável, sendo denominado por Lacan, de menos um "- 1". Assim, a singularidade que marca o sujeito, sua identidade mais íntima, é para ele, ao mesmo tempo, estranha e exterior, o que nos remete ao que Freud fez alusão em seu texto, "O Estranho" (1919/1976), e ao conceito lacaniano de extimidade, que é o mais próximo, o mais interior, sendo exterior. O êxtimo não se opõe ao íntimo, bem ao contrário: o êxtimo é o mais íntimo que se encontra no exterior.

Nos anos 70, Lacan, em Televisão (1972-1993), profetizou sobre escalada do racismo, com o desaparecimento do Outro e a expansão da ordem capitalista. O que ele vislumbrou, para a contemporaneidade, foi a imposição de um modo de gozo, o capitalista, uma vez que "no descaminho de nosso gozo só há o Outro para situá-lo” (LACAN, 1973/1993, p. 58).

A segregação, por sua vez, apresenta-se em Lacan referindose ao laço social, ou seja, sobre o discurso. Lacan postula que a origem da fraternidade é a segregação. Não há coletivo ou laço social sem exclusão, sem segregação, pois não existe um gozo social unificado, há várias modalidades de gozo que são escolhidas por cada cultura. O que faz nossa cultura ser marcada pela segregação é o fato de o discurso do capitalista e o discurso da ciência tenderem a universalizar, através do engodo, que todos têm o mesmo acesso ao gozo, consequência do discurso científico sobre o campo social.

Lacan se serviu de um exemplo concreto da articulação entre os fenômenos de segregação e o discurso: o isolamento dos loucos. As consequências do discurso da ciência sobre a subjetividade implicam que o sujeito exista somente como sujeito do saber científico, ou, para dizê-lo de outra maneira, exista um saber sem sujeito. Outra consequência são os efeitos de nomeação, pois as particularidades e singularidades do sujeito classificado se perdem e passam a ser, pela lógica das classificações, aquilo em que o indivíduo se transformou, depois de definido e incluído em determinada categoria, desdobrando-se num esvaziamento subjetivo,

Esse ideal universalizante e uniformizante, encontrado nos "impasses da época" - época de "todos iguais, e/ou para todos" - tem, como contrapartida, um efeito crescente de segregação. Ou seja, existe uma estrutura pela qual, quanto mais se encaminha para o universal, mais se segrega o particular. $\mathrm{O}$ 
particular refere-se ao que resta denegado, recalcado, à função estruturante da falta do Outro; é a castração, o mal-entendido que porta cada um dos falantes que somos, desde o nascimento.

Ao se analisar a cultura contemporânea, constata-se que a lógica de homogeneização e segregação está cada vez mais forte. O sintoma social apresenta-se, no seu ponto de vista, homogeneizado, com predicados universalizadores. Quanto mais se recalca e se tenta homogeneizar, mais aparecerá a rejeição, mais pesados e violentos serão os atos. O sintoma é o modo particular pelo qual o sujeito goza de seu inconsciente, mas, quando esse gozo não passa pelo Outro do inconsciente, quando esse laço se rompe, temos o sintoma social. Há sintoma social na anulação do laço com o Outro do inconsciente.

$\mathrm{Na}$ época do Outro que não existe, certas identificações se cristalizam em um significante mestre, para que os sujeitos que os utilizam se aliviem do sentimento que lhes impõe a angústia da castração. Nela comprova-se a fragilidade da proposta identificatória das supostas comunidades de gozo (gays, alcóolatras, anoréxicas...), que exigem de todos uma confissão generalizada de gozo, questão impossível. A lógica que dominaria a contemporaneidade seria, por conseguinte, uma lógica que se apoia na fragmentação, na dispersão e na multiplicidade. O predomínio do discurso da ciência, que imprime pressa em dar respostas generalizadoras às demandas de igualdade entre os homens, esvazia o singular do desejo.

\section{IDENTIFICATION AND THE CONTEMPORARY SEGREGATION PROCESSES}

\section{ABSTRACT}

The process of identification is essential in contemporary discussion about the social bonds and the new forms of segregation, and is closely linked to feelings of aversion and hostility present in every loving relationship that lasts for some time. This "narcissism of small differences" would be on the basis of the mechanisms that engender the segregation processes in culture. Lacan takes up the issue of identification proposed by Freud, which can be named hysterical, narcissistic or imaginary, and deals with the question of the other in us. Thus, the uniqueness that marks the subject, their most intimate identity, is for him, at the 
same time, strange and foreign, which brings us to what Freud (1919/1976) alluded in his text "The Stranger", and to the Lacanian concept of extimacy. For Lacan, the difference in a group only happens by hostility or exclusion of a different one. Contemporaneously, with the expansion of the capitalist order and the scientific ideal, we see the multiplication of identifications supply that impose a homogenization of enjoyment that can be designated as a manifestation of the Other of culture: what is not going well and reports a dysfunction in the relationship between humans and the culture that sustains them. These identifications segregate insofar as their manifestations signal failure points in the civilization project and can be taken as flaws in the social bond. School failure, child abuse, urban violence and drug addictions are examples of such occurrences.

Keywords: Identification.Segregation.Freud.Lacan. Contemporaneity

\section{REFERÊNCIAS}

FREUD, Sigmund. O Estranho. In: FREUD, Sigmund. Edição Standard Brasileira das Obras Psicológicas Completas de Sigmund Freud. Rio de Janeiro: Imago, 1919-1996. v. XVII.

FREUD, Sigmund. Psicologia de grupo e a análise do ego. In: FREUD, Sigmund. Edição Standard Brasileira das Obras Psicológicas Completas de Sigmund Freud. Rio de Janeiro: Imago, 1921 - 1996. v. XVIII

FREUD, Sigmund. O mal-estar na civilização. In: FREUD, Sigmund. Edição Standard Brasileira das Obras Psicológicas Completas de Sigmund Freud. Rio de Janeiro: Imago, 1930 1996. v. XXI

LACAN, Jacques. O seminário, livro 7: A ética da psicanálise. Rio de Janeiro: Jorge Zahar, (1959-1960)-1988.

LACAN, Jacques. O seminário: livro 9: A Identificação. Centros de Estudos Freudianos do Recife, (1961-1962) -2003.

LACAN, Jacques. O seminário, livro 17: O avesso da psicanálise. Rio de Janeiro: Jorge Zahar, (1969-1970) - 1992.

LACAN, Jacques.Televisão. Rio de Janeiro: Jorge Zahar Editor, (1972) - 1993.

Recebido em: 26/06/2015

Aceito em: 09/11/2015 